\title{
Towards Attaining Reliable and Efficient Green Cloud Computing Using Micro-Smart Grids to Power Internet Data Center
}

\author{
Mohammed Mansur Ibrahim¹, Anas Ahmad Danbala², Mustapha Ismail ${ }^{3}$ \\ ${ }^{1}$ Department of Mathematics \& Computer Science, Federal University of Kashere, Kashere, Gombe State, Nigeria \\ ${ }^{2}$ Trans. Access Planning Engineer, Mobile Telecom. Network (MTN) Abuja Switch Office, Abuja FCT, Nigeria \\ ${ }^{3}$ Department of Mathematics \& Comp. Sci., Gombe State University, Gombe, Gombe State, Nigeria \\ Email: mansuribrahim59@gmail.com, anasdanbalaahmad@gmail.com, almustea1@gmail.com
}

How to cite this paper: Ibrahim, M.M., Danbala, A.A. and Ismail, M. (2019) Towards Attaining Reliable and Efficient Green Cloud Computing Using Micro-Smart Grids to Power Internet Data Center. Journal of Computer and Communications, 7, 195-205. https://doi.org/10.4236/jcc.2019.77016

Received: May 28, 2019

Accepted: July 15, 2019

Published: July 18, 2019

Copyright () 2019 by author(s) and Scientific Research Publishing Inc. This work is licensed under the Creative Commons Attribution International License (CC BY 4.0).

http://creativecommons.org/licenses/by/4.0/

\begin{abstract}
Energy generation and consumption are the main aspects of social life due to the fact that modern people's necessity for energy is a crucial ingredient for existence. Therefore, energy efficiency is regarded as the best economical approach to provide safer and affordable energy for both utilities and consumers, through the enhancement of energy security and reduction of energy emissions. One of the problems of cloud computing service providers is the high rise in the cost of energy, efficiency together with carbon emission with regards to the running of their internet data centres (IDCs). In order to mitigate these issues, smart micro-grid was found to be suitable in increasing the energy efficiency, sustainability together with the reliability of electrical services for the IDCs. Therefore, this paper presents idea on how smart micro-grids can bring down the disturbing cost of energy, carbon emission by the IDCs with some level of energy efficiency all in an effort to attain green cloud computing services from the service providers. In specific term, we aim at achieving green information and communication technology (ICT) in the field of cloud computing in relations to energy efficiency, cost-effectiveness and carbon emission reduction from cloud data center's perspective.
\end{abstract}

\section{Keywords}

Cloud Computing, Internet Data Center, Green IT, Energy Efficiency, Micro-Smart Grids

\section{Introduction}

Cloud computing is an area of interest in the field of information and commu- 
nication technologies (ICT) due to the minimisation of operational cost associated with it. Many organisations such as business, government and academic institutions utilised cloud services nowadays from software, a platform to infrastructure to have proper and flexible management of multiple IT resources [1]. However, due to extensive internet coverage across the globe, it became imperative to directly focus on green technologies to achieve minimum energy consumption concerning IT resources towards environmental protection. Cloud computing appeared to be the solution towards achieving green ICT without compromising the quality of internet services. The technology offers tremendous benefits to the users in terms of having their considerable resources stored and managed by the service providers instead of managing their systems [2]. Additionally, economic and environmental issues related to cloud computing with respect to power consumption can be solved through micro grid application, thus, through providing information exchange that is extensive intra- and inter-utility together with numerous real-time information in a cost-effective manner [3]. The smart grid is an enhancement of the traditional power grid whereby it utilises two-way communication of the flow of electricity to produce automated and distributed advanced network for energy distribution [4]. This paper focuses on how to mitigate issues of high energy consumption, cost and environmental pollution related to activities of IDCs to achieve green cloud computing service.

The paper first introduces the paradigm of green IT together with concern areas, and that is followed by cloud computing, models and services offered by the cloud. The paper then introduced smart micro-grids in brief and most importantly, how the concept of green IT in the area of IDC for cloud computing could be achieved with the smart micro-grids' application. The paper also carefully studied the existing practice based on the perspectives of energy and cost efficiency together with a carbon emission of the IDCs and projected a convincing solution to IDC issues highlighted.

\section{Green IT}

Green IT is a new computing model that transformed IT resources into energy consumption efficiency concerning cost and power. The IT resources in interest here are the IDCs and other IT facilities. The application areas for green IT includes proper power management, server visualisation, design of data centers plus eco-labelling for IT products. Other important areas include environmental sustainability plus the design and energy efficient resources [5]. While [6] defined green IT as a "study area that deals with designing, manufacturing, using and disposing of computers, servers and associated sub-systems such as monitors, printers, storage devices and networking and communication systems efficiently and effectively with minimal or no impact on the environment". The idea of green IT aims at realising the cost-effectiveness of IT infrastructure by improving systems performance and at the same time respecting social and ethical responsibilities. Additionally, green IT definition suggests the inclusion of green 
IS to have a complete description. Based on that, green IT is defined as a combination of people, processes together with software and information technologies to support different institution or societal set goals. This definition emphasised that both green IT and green IS can bring about tremendous and realistic initiatives to promote the sustainability of business processes and add to a different aspect of organisational responsibilities together with private green IT initiatives.

However, in general term green IT is regarded based on the perception of "environmental sustainability, the economics of energy efficiency in computing, power management, data centre design and development. Likewise, virtualisation of server, proper recycling method and disposal, complying with regulatory bodies in terms of green metrics; assessment tools and methodology, environmental-related risk mitigation use of renewable energy resources and eco-labelling of IT products" [7]. Therefore, it is imperative to have a good understanding of these green IT concern areas in order to mitigate the issues. Below subsection present a foundation for a good understanding of these green IT concern areas.

\section{1) Concern Areas of Green IT}

There are numerous concern areas in the field of green IT that attracted much attention, and a lot of research was carried out in these areas to achieve an environmentally friendly and cost-effective IT resource management. The most concern areas that were given much attention recently are power management and energy efficiency. While areas like sustaining the natural resources by providing a green scenario with cost-efficiency, carbon emissions reduction, virtualization of servers and management of servers were less focused in the past and hence require much attention in order to overcome the challenges associated with these areas [5] [6] Figure 1. below presents the major green IT concern areas.

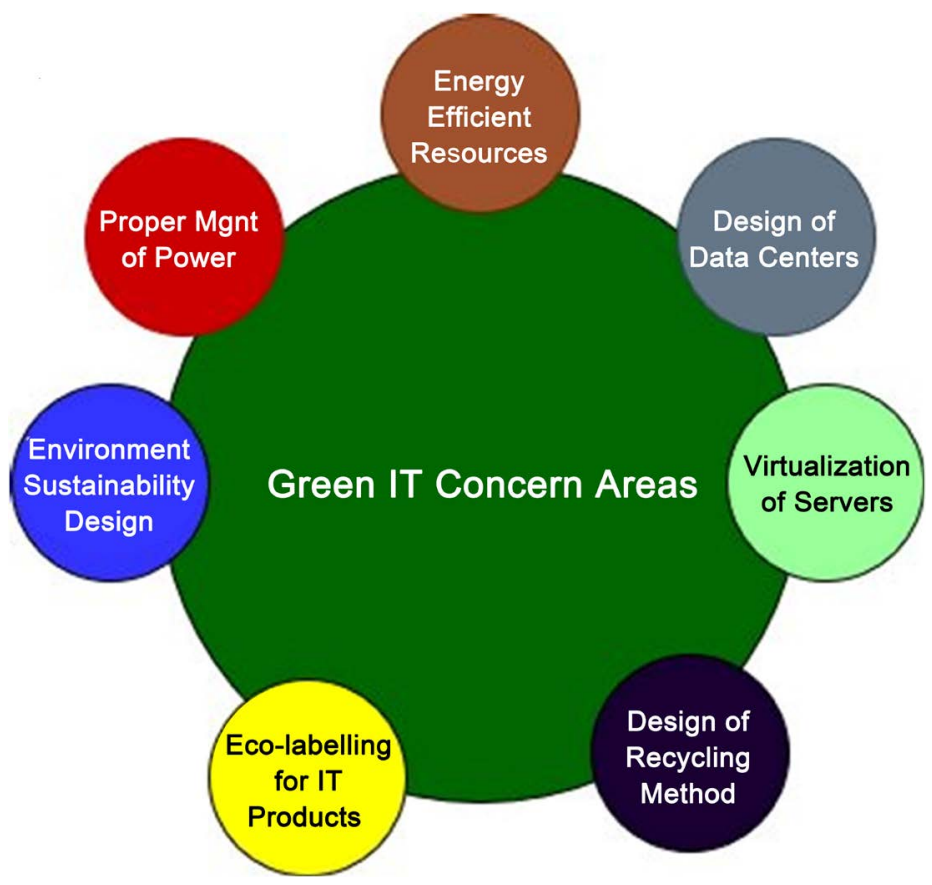

Figure 1. Concern areas of green IT. 


\section{2) Green Computing}

More so, have explained the concept of green IT; it is important to have a good understanding of the term green computing as well. The idea of green computing means the way and manner computers and other IT resources are used with high regard of the environment to achieve energy efficiency, the proper energy consumption of resources with minimal electronic waste. Technically, green computing involves two aspects which are as follows;

- In terms of software technology with a particular focus on enhancing storage, program and energy efficiency.

- In terms of hardware with interest in technologies with lower energy consumption together with economic efficiency in respect of recycling [5]. However, have gone through the field of green IT, it's now imperative and ideal to discuss the concept of cloud computing as a whole.

\section{Cloud Computing}

It means accessing computing product and services via the cloud powered by external parties through a remote server [8]. In another perspective cloud computing referred to applications deployed as a service via the internal network with a physical data centre responsible for implementing and managing these services [9]. While [10] [11] defined cloud computing as a subsidiary of grid computing and the model is based on pay-per-use. It provides efficient use of energy, affordable price technologies that help when accessing, sharing of services together with storage and management of resources. Of course, the idea has numerous advantages which among them are; network access, infrastructure sharing, reduction of cost of operations, maintainability, reliability, flexibility together with different service, and so on. Figure 2 depicts the concept of cloud computing model or services.

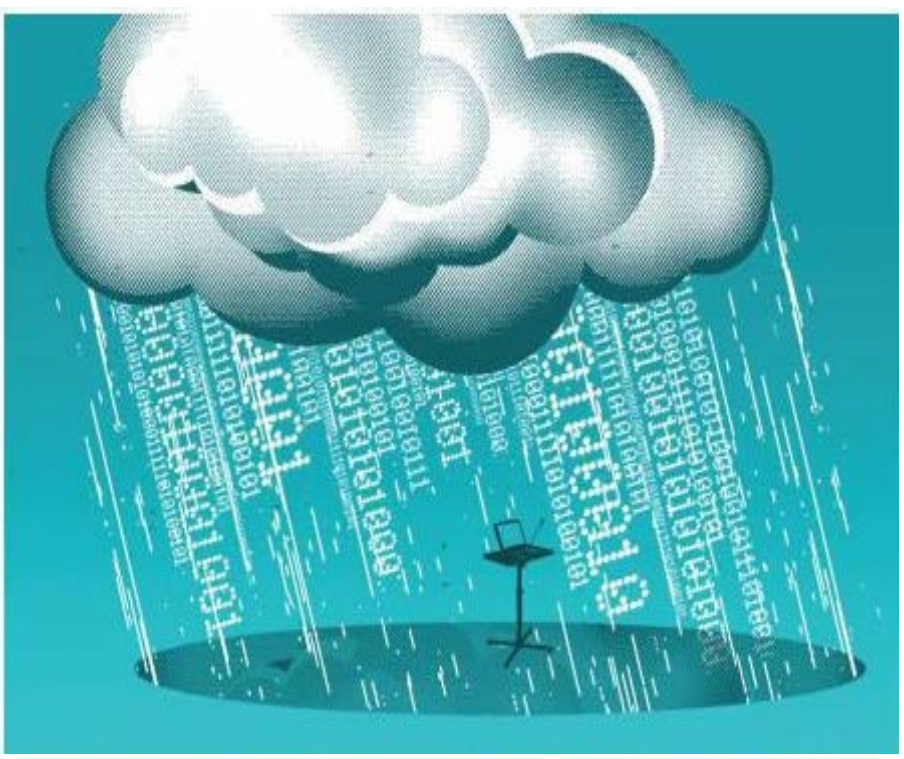

Figure 2. Cloud computing scenario [8]. 
Additionally, it is a storage, network and another vital aspect of computing services that can be deployed and run arbitrary software which includes in both operating system and applications. Also, here the user has no business with management and control of cloud infrastructure rather the end user can have control over the operating systems applications, storage and some limited control over specific networking components like host firewalls [1] [5] [11] [12].

\section{1) Deployment Models of Cloud Computing}

The whole idea of cloud computing is to offer on-demand services to end-consumers. There are three different deployment models namely; Public cloud, Private cloud and hybrid cloud [2] below details on the explanation of these three deployment models.

\section{2) Public Cloud}

The model is designed in such a way that any user can access it based on pay-as-you-go manner and of course hosted by the internet. The famous public clouds are as follows; Amazon Web Services (AWS), Google App Engine, Microsoft Aure and all of them support the three cloud computing services namely; IaaS, SaaS and PaaS. For instant, Google App Engine is a public cloud offering application development platforms, and Salesforce.com is also a public cloud that provides software as a service while Amazon EC2 is a public cloud that gives infrastructure as a service. Public cloud is basically for commercial purposes [2] [5].

\section{3) Private Cloud}

The private cloud serves a particular enterprise, and the responsibilities of hosting the network lie in that specific enterprise. Cloud infrastructure is managed by the enterprise together with the network design to serve one or fewer more organisations. Part of its benefits is that it allows greater access and control over the infrastructure with much security since its access is limited to one party [2] [5].

\section{4) Hybrid Cloud}

However, hybrid cloud emerged from public and private clouds diffusion. The model allows organisations to outsource less priority information processing to the public cloud while keeping classified services and data under their control. It takes into account three computing services which are stored as a service, processing as a service and software as a service. Storage service permits the user to save their data safely on the cloud, processing as service allows the user to outsource certain computational services while software as a service gives the users the ability to merge the above two services and outsource them all to the cloud with little utilisation of processing power terminal home. Hybrid cloud basically can move data across the two mentioned clouds through their interfaces [2] [5].

\section{Cloud Computing Services}

Services of the cloud mean a chunk of services powered by the data centres via the cloud with the use of the internet. These services are categorized into three major categories, namely; Platform as a Service-PaaS, Software as a Service-SaaS and Infrastructure as a Services-IaaS. Although there is a fourth cat- 
egory communication as a service but is being regarded as a subset of software as a service and it's mainly related to industries that used hosted services of IP telephony [5].

a) Platform as a Service-PaaS: The ability for the end user to access or acquired applications platforms which are being developed using programming languages libraries, services and tools powered by the cloud owner. The user has no business with the maintenance of cloud infrastructures such as servers, network, storage and operating systems but can manage the powered applications with the ability to configure settings for the applications with hosting environment. In a simple term, PaaS comprises programming environment and execution environment, e.g. commercially Google Application Engine [1] [11] [12].

b) Software as a Services-SaaS: SaaS deals with different applications required by many end users across a different geographical location for their daily routine work. Example of such services is words processors and spreadsheets. End-User doesn't manage or control the cloud in terms of network servers, operating systems, storage and individual application access but can have some limited user-specific application configuration settings [1] [5] [11] [12].

c) Infrastructure as a Service-IaaS: Cloud services developed on top of bare hardware which is achieved by the use of virtualization technologies, the model offered a user with services such as processing,

Subsequently, this paper would focus on how to mitigate issues related IDCs that power these cloud computing services in terms of high energy consumption and related environmental pollution for an environmentally friendly IDC.

\section{A Proposed Solution to Alarming High Energy Consumption and Related Issues of IDCS}

\section{1) Micro Smart Grids}

Micro-Smart grids evolved out of microgrids environment as a smaller version of today's big centralised power systems. It is capable of generating, distributing and regulating the flow of electricity to consumers. Smart micro-grids can form a network with one another as well as a central grid to add to capacity, efficiency as well as reliability. Due to the fact that micro-grids are not often owned and operate by a utility company, that allows micro-grids to be built, owned and run by an entity, be it community, neighborhood, university, corporation, hospital, individual or a corporate body with absolute legal right over their power infrastructure (i.e. power transmission lines, meters, generation source etc.) [13]. There are two principal operational modes in smart micro-grids, i.e. islanded mode and grid-connected mode. Operation is said to be in islanded mode when SMGs supply their loads utilising different energy resource, e.g. energy storage devices, back up with renewable generators. SMG can transact with the primary grid in terms of buying or selling of energy. Other essential components of SMG include generation systems, load, energy storage systems (ESS) and of course, the energy management system (EMS). The gener- 
ation part comprises of many generators and a conventional one serving as back up in case of failure. While EMS has to do with energy scheduling for another component in SMG, and the overall load in the SMG is required by the data centre to process the service request distributed from the front-end servers [14].

2) Efficient and Reliable Cloud Computing Application embedded with Smart grid

Generally, energy has been considered to be playing a vital role in the shaping of the human condition. Energy production and consumption are the main activities of social life due to of $21^{\text {st }}$-century people's necessity for energy as a fundamental for existence. Hence, the standard of living and quality of a civilisation is directly dependent on the quantity of energy a society uses. Energy efficiency is regarded as the best conservative approach to provide safer and affordable energy for both utilities and consumers through the enhancement of energy security and the reduction of energy emissions. With the exponential growth in the power industry, there is a need for continuously vast and real-time computing and storage capacity. The amount of these resources will exhibit a uniformly distributed growth at all levels of the grip; as such, the importance and significance of the cloud model come into play. The scalable and flexible characteristics of Cloud computing, with its capability to handle large amounts of data, make it the most straight forward and best-suited way to this kind of smart grid applications. The development of a smart grid requires large-scale real-time computing capabilities for the processing of communication, the transportation and also storage of huge amount of transferable data. Cloud computing helps to unbundle the smart grid by providing automatic updates, remote data storage and also reduced maintenance of IT systems, thereby saving money, manpower and energy [15]. Several problems have been encountered in the conventional smart grid architecture which does not have cloud integration. Some of these issues include the following below;

- Cyber-attacks such as Distributed Denial of Service could arise from the Master-Slave architected grid (without cloud).

- If there is any failure in the Master-Slave architecture, the system could also fail.

- The limited server capacity can only serve for several users (customers).

- Limited memory and storage will pose a significant problem when serving a large number of customers.

- There is a need for management and stability issues [16].

However, scholars have proposed several solution concepts and approaches regarding demand response and micro-grid management and efficiency. The implementation of dynamic pricing is a basic approach that can be used to address energy management. Additionally, the integration of cloud into the microgrid system will make it possible to schedule incoming jobs to be carried out by the availability of resources, their order of priority and other applicable constraints. In the course of peak hours, there are more messages from the smart 
meters than those in the non-peak hours. Nonetheless, at this moment, scheduling of incoming jobs from users takes place according to their order of priority, availability of resources and applicable constraints. These issues can be addressed conveniently by the integration of dynamic bandwidth allotment mechanism using cloud application. The allotted bandwidth during peak-hour is higher than that in the non-peak hour, which serves all the incoming jobs simultaneously [17].

3) Energy Consumption, Cost-Efficient and Carbon Emissions Reductions of Cloud Computing IDCs with Smart Microgrids.

In cloud computing, internet data centres are the backbone of the operation, which is also responsible for high energy consumption together with cost and carbon emission at the same time. To realise a green concept in the area of data centres, Smart-Micro-grids application would support lower electricity distribution loss, higher utilisation of ratio concerning energy cost and free carbon emission to the environment. One of the concerned areas of green IT in cloud computing is internet data centres, due to it high power consumption and bills associated with it, for example, Google annual power consumption is about 6.3 * 105 MWh which is about $\$ 38$ million respectively, in the year 2010 google consumed $2260 \mathrm{MWh}$ translating into more than 1.35 billion dollar electricity bill. Another concern area of green IT concerning cloud computing is the alarming environmental impact associated with internet data centres, for example in the year 2008 carbon emission of data centres was $0.6 \%$ of the global carbon emission, and this proportion of $0.6 \%$ was projected to reach $2.6 \%$ by 2020 . However, for a data centre to achieve social responsibility, these mentioned problems need to be addressed together. More so, in a quest to mitigate these issues associated with internet data centres IDCs, smart micro-grids evolved from smart grid environment. Smart micro-grids have the potential of providing fault isolation and easy kind of distributed generation handling. And without a doubt there are many benefits of running internet data centres with smart micro-grids which are as follows;

- Cooling power consumption can be achieved through direct current microgrids by reducing the distribution loss, which in turn would lower the cost of energy.

- Transaction of power between smart microgrids and the primary grid can reduce waste of renewable energy and lower down carbon emission.

- In case of power failure from the central grid, smart microgrids would pick up the power operation in islanded mode. Hence the rate of carbon emission can also be exploited to minimise energy cost and bring down the carbon emission.

However, in the quest to move towards achieving a socially responsible IDC, operations must focus on cutting energy cost and carbon emission reduction simultaneously and that we believed can be realised through the use of smart microgrids. On the real scenario of green IDC, the operator on that regards would have in place different IDCs in self-owned SMGs with independent elec- 
tric power regions (ERs) [14] [15] [18] [19] [20].

Another way of addressing energy management and energy efficiency is by adopting the concept of Cloud-Based Demand Response (CDR) for getting fast response times in large scale deployment. The CDR presents a master/slave demand response model whereby both the smart meters and the Home Energy Management System (EMS) act slaves, while the utility acts as the master. In this situation, the CDR controls data-centric communication, subscriber/publisher and topic-based group management, rather than IP-centric communication. Furthermore, two cloud-based demand response models are to be established, namely as follows:

a) data-centric communication.

b) topic-based group communication.

The CDR approach can render a secure, reliable and scalable demand response. However, the demand response has an overhead problem in the cause of implementing a private cloud for a small-sized network, which may include implementation cost and the choosing of an appropriate strategy [21]. Therefore, this study is proposing a solution to the said issues via model design with a mathematical algorithm to support the model in order to achieve a practical solution to the issues.

\section{Conclusion}

The paper presents an idea of how green cloud computing can be attained with regards to alarming energy consumption and carbon emission of cloud data centres. Smart micro-grid was found to be suitable and reliable in mitigating such issues with a high sense of optimality. Although achieving green IT in cloud computing doesn't stop at addressing IDC issues alone. Instead, it requires full attention in other green IT concern areas such as virtualisation of servers, proper power management and environmental sustainability design concerning IT products. And to realise a comprehensive green cloud computing service, more research should focus on the areas mentioned above. However, to make this idea possible, we recommend a model design with a possible mathematical algorithm to support and validate the model.

\section{Acknowledgements}

Much gratitude to our lecturer Assoc. Professor Mehmet Toycan, Director Telecommunication Research Center Cyprus International University via Mersin 10 Turkey, for his valuable comments and guidance while developing this paper. And also, to all the reviewers, we say thank you for finding the time to review and recommend some improvement on this research paper.

\section{Conflicts of Interest}

The authors declare no conflicts of interest regarding the publication of this paper. 


\section{References}

[1] Da Cunha Rodrigues, G., Calheiros, R.N., Guimaraes, V.T., Santos, G.L., de Carvalho, M.B., Granville, L.Z., Tarouco, L.M. and Buyya, R. (2016) Monitoring of Cloud Computing Environments: Concepts, Solutions, Trends, and Future Directions. In: Proceedings of the 31 st Annual ACM Symposium on Applied Computing, ACM, New York, 378-383. https://doi.org/10.1145/2851613.2851619

[2] Pandya, S.S. (2014) Green Cloud Computing. International Journal of Information and Computation Technology, 4, 431-436. http://www.irphouse.com/ijict.htm

[3] Vaccaro, A., Popov, M., Villacci, D. and Terzija, V. (2011) An Integrated Framework for Smart Microgrids Modeling, Monitoring, Control, Communication, and Verification. Proceedings of the IEEE, 99, 119-132. https://doi.org/10.1109/JPROC.2010.2081651

[4] Xi, F., Misra, S., Xue, G. and Yang, D. (2012) Smart Grid-The New and Improved Power Grid: A Survey. IEEE Communications Surveys \& Tutorials, 14, 944-980. https://doi.org/10.1109/SURV.2011.101911.00087

[5] Patel, Y.S., Mehrotra, N. and Soner, S. (2015) Green Cloud Computing: A Review on Green IT Areas for Cloud Computing Environment. 2015 International Conference on Futuristic Trend in Computational Analysis and Knowledge Management, Noida, India, 25-27 February 2015, 327-332.

[6] Mithas, S., Khuntia, J. and Roy, P.K. (2010) Green Information Technology, Energy Efficiency, and Profits: Evidence from an Emerging Economy. ICIS 2010 Proceedings. Paper No. 11.

[7] Murugesan, S. (2008) Harnessing Green IT: Principles and Practices. IT Professional, 10, 24-33. https://doi.org/10.1109/MITP.2008.10

[8] Computing, C. (2011) Cloud Computing Privacy Concerns on Our Doorstep. Communications of the ACM, 54, 36-38. https://doi.org/10.1145/1866739.1866751

[9] Armbrust, M., Fox, A., Griffith, R., Joseph, A.D., Katz, R.H., Konwinski, A., Lee, G., Patterson, D.A., Rabkin, A., Stoica, I. and Zaharia, M. (2009) Above the Clouds: A Berkeley View of Cloud Computing. Technical Report No. UCB/EECS-2009-28, University of California at Berkeley, Berkeley, CA.

[10] Buyya, R., Yeo, C.S., Venugopal, S., Broberg, J. and Brandic, I. (2009) Cloud Computing and Emerging IT Platforms: Vision, Hype, and Reality for Delivering Computing as the 5th Utility. Future Generation Computer Systems, 25, 599-616. https://doi.org/10.1016/j.future.2008.12.001

[11] Zhang, L., Zhang, L., Ge, M.-H. and Bi, X.-L. (2011) Research and Application on the Cloud-Computing-Based Power Dispatching IT Architecture. 2011 Asia-Pacific Power and Energy Engineering Conference, Wuhan, 25-28 March 2011, 1-4. https://doi.org/10.1109/APPEEC.2011.5748813

[12] Mell, P. and Grance, T. (2011) The NIST Definition of Cloud Computing: Recommendations of the National Institute of Standards and Technology. Computer Security Division Information Technology Laboratory National Institute of Standards and Technology, Gaithersburg, MD, 20899-8930.

[13] Liang, Y., Jiang, T. and Zou, Y. (2016) Real-Time Energy Management for Cloud Data Centers in Smart-Microgrids. IEEE Access, 4, 941-950. https://doi.org/10.1109/ACCESS.2016.2539369

[14] Popeang, J. (2012) Cloud Computing and Smart Grids. Database Systems Journal, 3, 57-66.

[15] Liang, Y., Zou, Y. and Wang, K. (2016) Online Energy Management for Data Cen- 
ters and Electric Vehicles in Smart Grid Environment. 42nd Annual Conference of the IEEE Industrial Electronics Society, Florence, Italy, 23-26 October 2016, 5415-5419.

[16] Naveen, P., Wong, K.I., Danquah, M.K., Sidhu, A.S. and Abu-Siada, A. (2016) Cloud Computing for Energy Management in Smart Grid-An Application Survey. IOP Conference Series: Materials Science and Engineering, 121, Article ID: 012010. https://doi.org/10.1088/1757-899X/121/1/012010

[17] Li, X. and Lo, J.-C. (2012) Pricing and Peak Aware Scheduling Algorithm for Cloud Computing. 2012 IEEE PES Innovative Smart Grid Technologies, Washington DC, 16-20 January 2012, 1-7. https://doi.org/10.1109/ISGT.2012.6175636

[18] Jiang, T., Liang, Y. and Yang, C. (2015) Energy Management of Internet Data Centers in Smart Grid. Springer, Berlin, Heidelberg. https://doi.org/10.1007/978-3-662-45676-7

[19] Kim, H., Kim, Y.J., Yang, K. and Thottan, M. (2011) Cloud-Based Demand Response for Smart Grid-Architecture and Distributed Algorithms. 2011 IEEE International Conference on Smart Grid Communications, Brussels, 17-20 October 2011, 398-403.

[20] Aliyu, A., Tayyab, M., Abdullah, A.H., Mohammed Joda, U. and Kaiwartya, O. (2018) Mobile Cloud Computing: Layered Architecture. 2018 Seventh ICT International Student Project Conference, Nakhonpathom, Thailand, 11-13 July 2018, 1-6. https://doi.org/10.1109/ICT-ISPC.2018.8523997

[21] Mohammed Joda, U., et al. (2019) Energy-Efficient Virtual Machine Allocation Technique Using Flower Pollination Algorithm in Cloud Datacenter: A Panacea to Green Computing. Journal of Bionic Engineering, 16, 354-366.

https://doi.org/10.1007/s42235-019-0030-7 